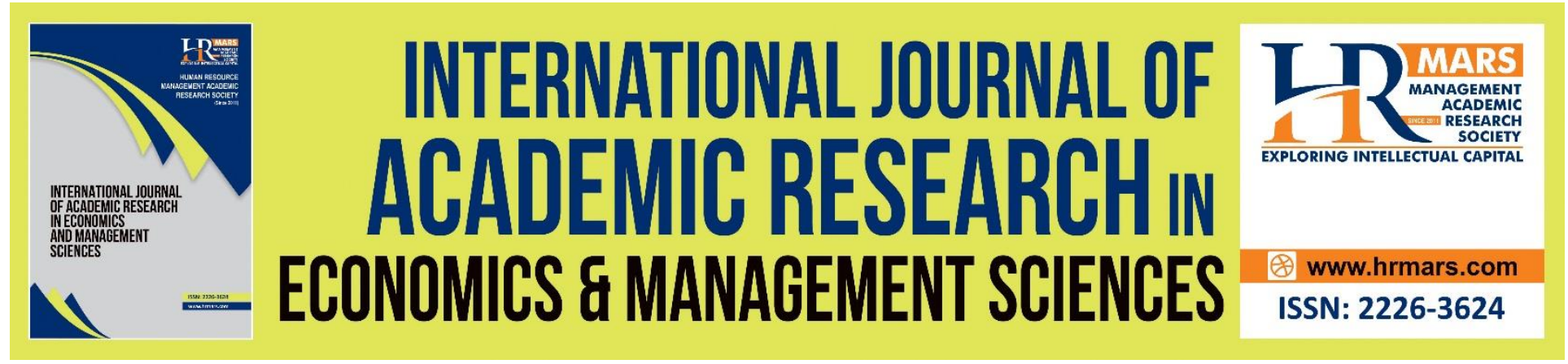

\title{
Economics and Environment Assessment of Smart Energy Electricity Meter for Residency Monitoring
}

Nurfadzilah Ahmad, Iman Syazwan Mohd Yusof, Mohd Firdaus Abdullah

To Link this Article: http://dx.doi.org/10.6007/IJAREMS/v11-i1/11136

DOI:10.6007/IJAREMS/v11-i1/11136

Received: 06 November 2021, Revised: 09 December 2021, Accepted: 26 December 2021

Published Online: 10 January 2022

In-Text Citation: (Ahmad et al., 2022)

To Cite this Article: Ahmad, N., Yusof, I. S. M., \& Abdullah, M. F. (2022). Economics and Environment Assessment of Smart Energy Electricity Meter for Residency Monitoring. International Journal of Academic Research in Business and Social Sciences, 11(1), 1-15.

Copyright: (c) 2022 The Author(s)

Published by Human Resource Management Academic Research Society (www.hrmars.com)

This article is published under the Creative Commons Attribution (CC BY 4.0) license. Anyone may reproduce, distribute, translate and create derivative works of this article (for both commercial and non-commercial purposes), subject to full attribution to the original publication and authors. The full terms of this license may be seen at: http://creativecommons.org/licences/by/4.0/legalcode

Vol. 11, No. 1, 2021, Pg. 1 - 15

Full Terms \& Conditions of access and use can be found at http://hrmars.com/index.php/pages/detail/publication-ethics 


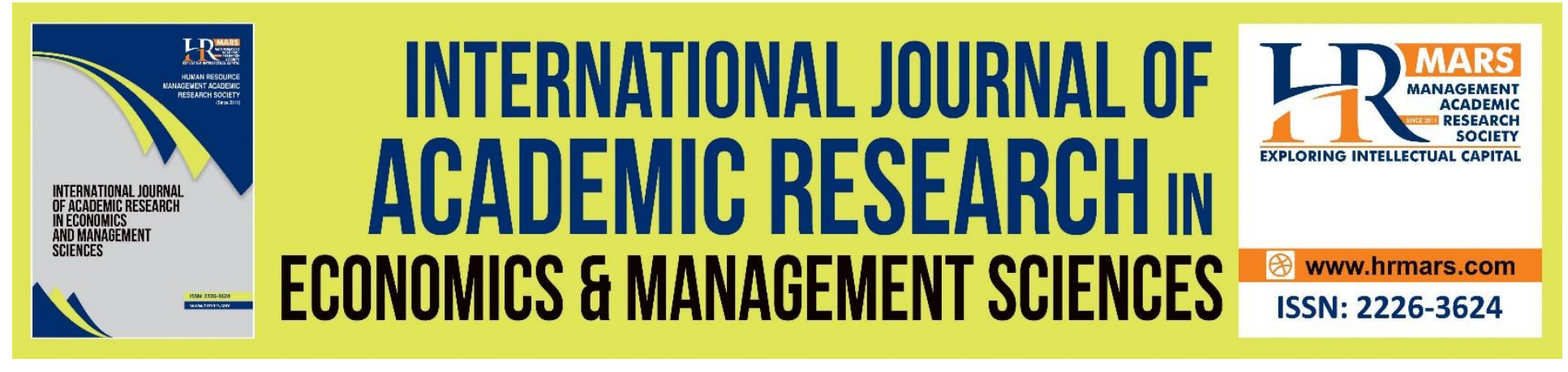

\title{
Economics and Environment Assessment of Smart Energy Electricity Meter for Residency Monitoring
}

\author{
Nurfadzilah Ahmad ${ }^{1}$, Iman Syazwan Mohd Yusof ${ }^{1}$, Mohd Firdaus \\ Abdullah ${ }^{2}$ \\ ${ }^{1}$ Solar Research Institute (SRI), UiTM Shah Alam, Shah Alam, Selangor, ${ }^{2}$ School of Electrical \\ Engineering, College of Engineering, UiTM Permatang Pauh Pulau Pinang
}

\begin{abstract}
The energy meter is a device to measure energy utilities and is crucial to determine the daily energy usage. However, the current energy meter can only record the amount of power consumed but is still lacking in the monitoring system for power consumption. This paper implemented the concept of an loT based energy meter using a simple low-cost NodeMCU microcontroller, an esp8266 Wi-Fi chip module and Blynk application. This device was constructed with an LED to represents the power consumption from the LED blinking with the base value set at 1000 pulse for 30 minutes, proportional to the energy meter time. This loT based device will count the pulse from LED blinking and store the energy reading to identify the Maximum Demand (MD) in a residence based on the time and date of the reading taken. We set a certain limit for the power consumption and once the limit is reached, this loT based device will send the notification through a Blynk application to enable users to control their energy consumption. This proposed design is beneficial in preventing any MD penalty to the users due to an excessive energy usage.
\end{abstract}

Keywords: Energy Meter, Esp8266, LDR, Maximum Demand

\section{Introduction}

Energy usage in residential, commercials and industrial area can be measured by the energy meter (Vendrusculo et al., 2007). Tenaga Nasional Berhad (TNB) is a typical energy supplier in Malaysia and is currently in the replacement phase to replace its electromechanical meters with an electronic meter for an upgrade and all the meters have been calibrated and tested to meet Malaysian ISO / IEC 17025:2005 requirements (Mudaliar \& Sivakumar, 2020). The reading of the energy consumed is defined by the LCD (Abate et al., 2019) of the meter provided the peak load from TNB whenever necessary. Because electricity cannot be stored, there must be efficient generation, transmission, and distribution capacities available for the highest demand (Abate et al., 2019). The Domestic Ordinary Power Consumers can be categorized into two types, singlephase and three-phase and all the electrical services can be measured in kilowatt-hours (kWh), referring to the kilowatt-hour energy consumption (Muralidhara et al., 2020). This device 
implements the loT concept to the energy meter that connects the device via the internet using a Wi-Fi module where the user can monitor their consumption using only a mobile phone that can connect many user accesses from one device to another. This device will monitor the consumption of load by counting the pulse of the energy meter, where the user will be notified when the pulse reaches the base line.

Different technologies have been developed to measure the power consumption of the consumer to measure the power consumption (Cebe \& Akkaya, 2019) and one of the main reasons for the breakthrough in the energy meter is that there is no software that notifies users of their energy use (Rafsanjani et al., 2020). In addition, the industrial sector that uses more power than the predestined level will be penalized. From the previous report, the loT energy meter was designed to track electricity demand by offering a system that can alert users when the peak demand occurs, where notification would be sent when excessive charges are used (Fettermann et al., 2020). When the energy usage can be registered, consumption can be reduced, which, in effect, considerably reduces costs. Energy demand measurement using an loT applications is increasing, as both numbers and specifications continue to rise for loT devices. Modernization of an loT based energy meter is new but a lot of work can be done to apply the same concept to an energy meter with an loT installation (Pocero et al., 2017).

The Internet of Things (IOT) technology enables a smooth and uncomplicated data transferring between both the energy suppliers and consumers, resulting in an easy and uninterrupted continuity of bill payments, and monitoring of energy usage (Pocero et al., 2017). Using the Wi-Fi module that connects the device to the Internet, the loT enables machines and sensors to be interconnected through the web (Avancini et al., 2019). IoT allows users to communicate or interact with non-living objects and also has the ability to move data through the internet without interaction between humans and humans or interaction between humans and computers (Diamantoulakis et al., 2015). Commencement of a Wi-Fi module will interrelate computer equipment, mechanical and digital devices, objects, animals, or people provided with unique identifiers (UIDs) to come out with a favorable loT device (Li et al., 2009). The consumer can track their consumption by using the loT energy meter through the internet, enable users to control and limit the usage (Li et al., 2009). Many devices can be interfaced using loT, and hence sensors and devices can be analyzed and controlled at any moment in any place with the presence of Wi-Fi. Therefore, Internet of Things (IOT) is medium that recommended for transferring the data over a network as upgrading the communication ability from a GSM or Bluetooth module which using mobile communication network to WiFi module which using local internet connection (Aziz et al., 2020). Internet connection can provide strong connection which it is needed to monitor the power consumption regularly in real time (Bansal et al., 2011). loT also can save the data into cloud-based application which it needed for analyzing the problem that transform into graph or others way.

Moreover, in a past few years, many recent studied and researched about the power consumption pattern to get the profile load for demand response (Diamantoulakis et al., 2015). However, in most studied and research, the power consumption pattern is not focus on process of appliances on every cycling and operation. As for this study, the research is more concern to the power consumption pattern on the operation mode of typical household appliance to provide enough information to the user. The main reason underlying the home appliance power consumption assumption is the lack of knowledge and information about detailed home 
appliance operating characteristics, and the lack of openly available measurement data (Hasanuzzaman et al., 2008). It is a difficult task to manually schedule the operation of appliances and would be almost impossible for any consumer. So a scheduling algorithm supported by suitable supporting technologies is needed to carry out the scheduling work each day (Kim et al, 2011). This project is therefore focusing on monitoring the real time of power consumption by using Internet of Things (IOT) based application. Therefore, from the analyzed result, the power consumption pattern of the appliance can be known in order to get power consumption algorithm or called as pattern of each different appliance.

\section{Materials and Methods}

Flow Chart

Figure 1 shows the flow chart of loT based energy meter project. The system started when the node MCU is uploaded to the board and after the code has been uploaded, the WiFi module will connect the project to the Wi-Fi and will start initializing the RTC, LCD and SD card module. The LCD will show an initial value of power and kWh and the input sensor which in this case, is the LDR module will runs by detecting the blinking at the LED circuit. If there are any pulse reading, the LCD will show the result of $k W h$, but if there is no pulse the sensor will read the pulse at energy meter again. ESP8266 WIFI module will upload the output of energy consumption in Blynk server. The data will be uploaded every 30 minutes and will be logged into an SD card. If the demand limit is reached, an alert notification will be sent to the Blynk apps. In the RTC (real time clock) coding, the time and date will be set for the first time when the program uploaded. Then, it will continue to follow the normal time until it is upload with an updated. 


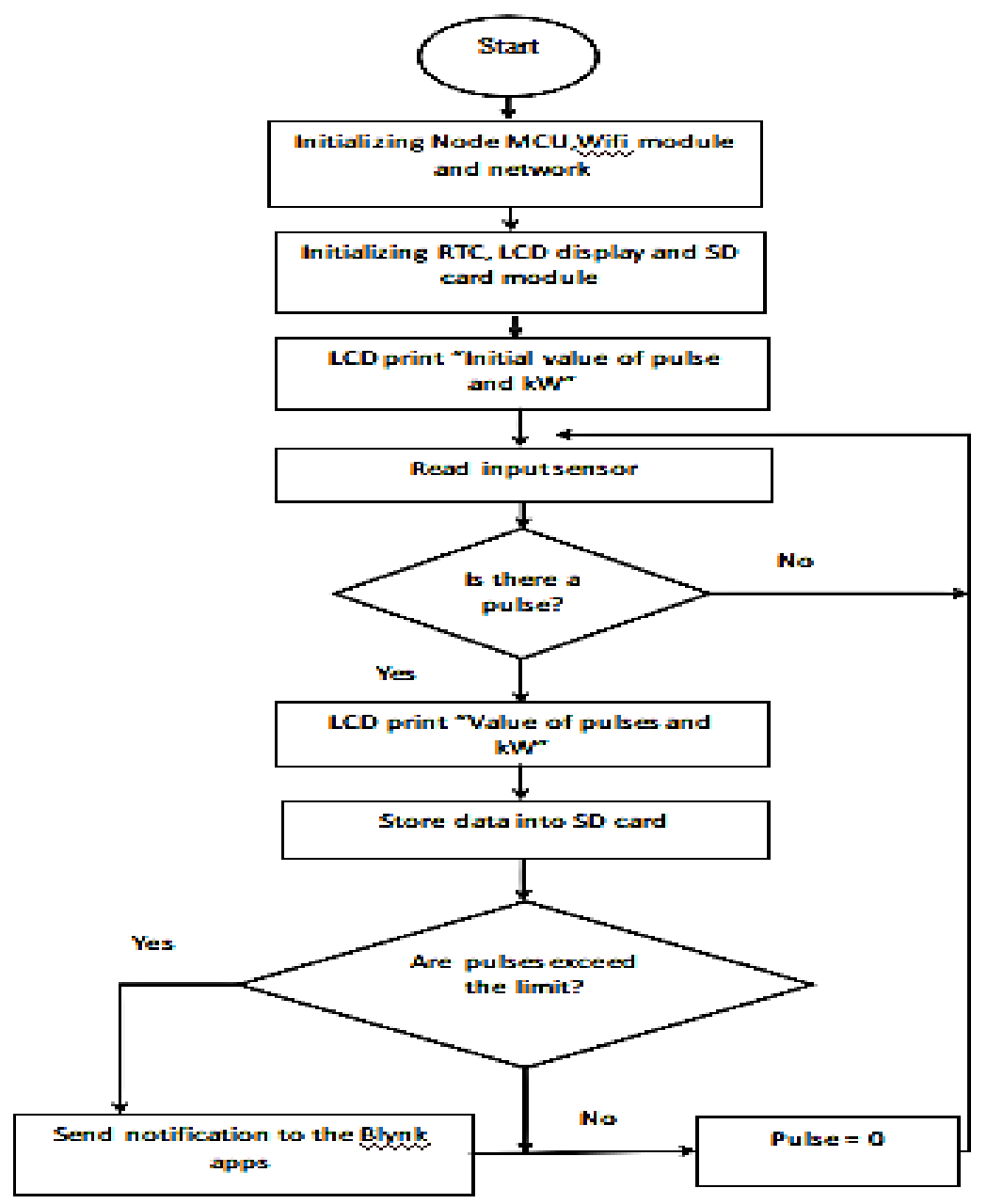

Figure 1: Flow chart of IoT based energy meter project

\section{IoT based Electricity Meter}

For this IoT based electricity meter to function accurately, the LDR was installed next to the LED circuit to detect the blinking pulse from the residency energy meter and following the input from the LED blinking, the LDR will send necessary information accordingly to the Node MCU. Data was collected every 30 minutes and was stored in the SD card. The RTC DS3231 serves as a device to incorporate the battery input and maintaining the time accuracy if the main power input was interrupted. This loT based electricity meter also comprises of a Liquid Crystal Display (LCD) to demonstrate the reading for power and $\mathrm{kWh}$, and the ESP8266 Wi-Fi module was connected to the internet to enable the data sending to mobile phone via cloud. For as long as the loT based electricity meter is connected to the internet, monitoring process of the energy usage can be done by consumers. To enable the monitoring directly from the smart devices, Blynk apps will received the data from Blynk server and consumers will be notified. Figure 2 shows the block diagram of the loT based electricity energy meter. 


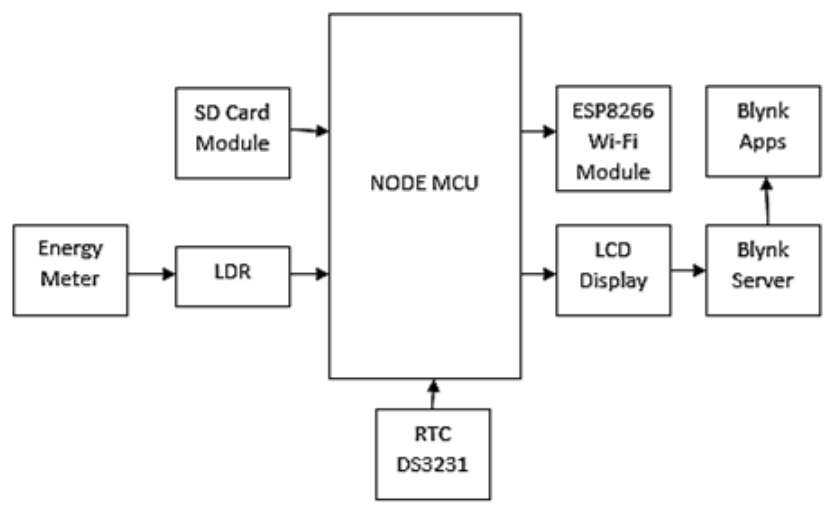

Figure 2: Block diagram of the lot Based Electricity Energy Meter

For Blynk connection the user need token to be used to login the app. Thus, the token must be included so the user can use the Blynk app in their phone to monitor the pulse count. To connect the $\mathrm{Wi}-\mathrm{Fi}$ module to the internet the password and network name must be included so the Wi-Fi module can connect to internet through the Wi-Fi. For this device the notification alert will be sent to the user if the kWh reached its limit as programmed. The limit of the $\mathrm{kWh}$ was set at $3 \mathrm{kWh}$ for the testing, so if the power exceeded $3 \mathrm{kWh}$ the notification will be sent to the user by sending notification "Alert!! Reach the limit!!" through the Blynk app. Attentively consumers will be alarmed of the total energy consumption when the limit is reached. Figure 3 shows the baseline code of notification.

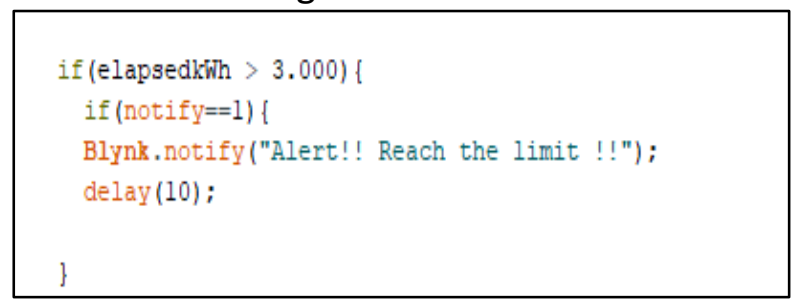

Figure 3: Baseline code of notification

Figure 4 shows the hardware loT based energy meter project connected to a residency energy meter. The working principle for this whole device starts from the LED blinking which indicates the consumption. The LED on the meter will blink as an indicator4when counting pulses and the LED placed next to the LDR sensor circuit caught the blinking pulses from the energy4meter. In addition, this loT energy meter was also equipped with an LCD to display the power counting in $\mathrm{kWh}$ which was translated from the total pulses count in 30 minutes duration. The LDR was also adjusted to the lowest sensitivity to prevent miscounting of pulse blinking and since the LDR was made of a high resistance semiconductor, it4can have4a resistance as low as several megaohms (Alahakoon \& Yu, 2016). Wi-Fi modem was installed to allow the device to be connected to the Wi-Fi internet connection via a Wi-Fi module as it is crucial to have a very highspeed internet for an accurate reading (Kishore et al., 2010). For monitoring purpose, Blynk application as the graphic interface for this project was used and this platform is available for installation in iOS and Android devices. From the observation during the data collection of the testing device, the time between one pulses from another pulse was about 4 seconds. Hence for a duration of 1 minute (60 seconds), 15 pulses were obtained resulting in 900 pulses per hour. 


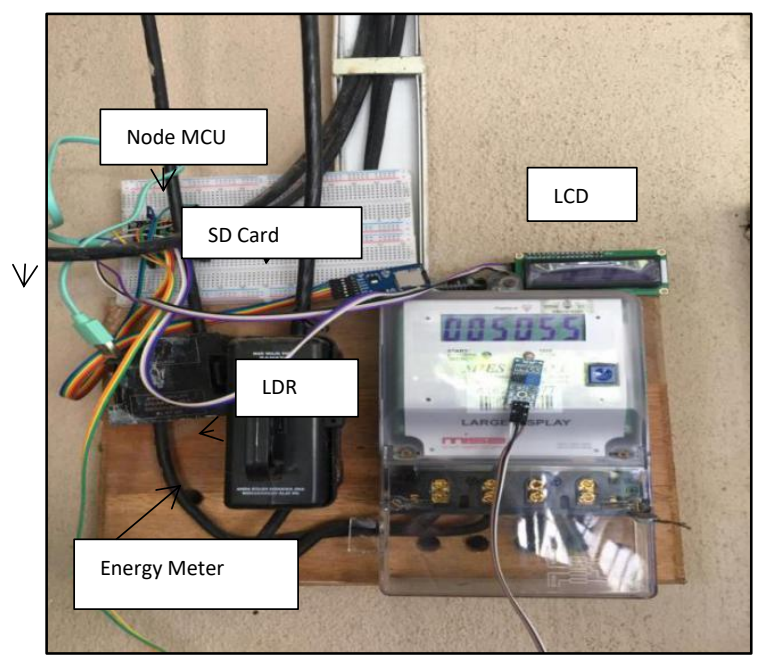

Figure 4: Hardware loT based energy meter project connected to a house energy meter

\section{Results and Discussion}

This section was divided into three sections, section A and section B were the hardware testing at residency energy meter and household appliances respectively, and section $C$ for the monitoring through Blynk apps.

\section{Section A: Result for hardware testing at residency energy meter}

The testing was taken in the morning, evening and at nighttime at a terrace house. The loT based energy meter hardware was connected to the house's energy meter for 30 minutes data collection and was summarized for the final 2 minutes for tabulation process. Table 1 shows the data power usage during testing for last two minute in the morning, evening and at night.

Table 1 shows the data during testing at a terrace house from 9am until 9.30am. This data shows the last 2 minutes of the data. It shows that the reading of the data maintained at 0.00 to $0.45 \mathrm{kWh}$ since there was less power usage at home in the morning. The data were also taken during testing at a terrace house from $12.51 \mathrm{pm}$ until $1.21 \mathrm{pm}$ and it shows the last 2 minutes of the data with the reading maintained at 0.00 to $2.548 \mathrm{kWh}$ and for night, data were taken from $8.51 \mathrm{pm}$ until $9.16 \mathrm{pm}$. For the last 2 minutes, the data maintained at 0.00 to $4.614 \mathrm{kWh}$. 
INTERNATIONAL JOURNAL OF ACADEMIC RESEARCH ECONOMICS AND MANAGEMENT SCIENCES Vol. 11, No. 1, 2022, E-ISSN: 2226-3624 @ 2022 HRMARS

Table 1: Data of power usage during testing

\begin{tabular}{cccccc}
\hline \multicolumn{2}{c}{ Morning } & \multicolumn{2}{c}{ Evening } & \multicolumn{2}{c}{ Night } \\
\hline TIME & kWh & TIME & kWh & TIME & kWh \\
\hline 9:28:18 & 0.0392020 & $\mathbf{1 3 : 1 9 : 2 7}$ & 2.4372020 & $\mathbf{2 1 : 1 4 : 2 7}$ & 4.3262020 \\
9:28:28 & 0.1332020 & $\mathbf{1 3 : 1 9 : 3 6}$ & 2.4482020 & $\mathbf{2 1 : 1 4 : 3 6}$ & 4.3582020 \\
9:28:37 & 0.2052020 & $\mathbf{1 3 : 1 9 : 4 5}$ & 2.4602020 & $\mathbf{2 1 : 1 4 : 4 6}$ & 4.3892020 \\
9:28:47 & 0.2952020 & $\mathbf{1 3 : 1 9 : 5 5}$ & 2.4712020 & $\mathbf{2 1 : 1 4 : 5 5}$ & 4.4192020 \\
9:28:56 & 0.2952020 & $\mathbf{1 3 : 2 0 : 4}$ & 2.4812020 & $\mathbf{2 1 : 1 5 : 4}$ & 4.4452020 \\
9:29:5 & 0.3062020 & $\mathbf{1 3 : 2 0 : 1 4}$ & 2.4882020 & $\mathbf{2 1 : 1 5 : 1 4}$ & 4.4742020 \\
9:29:15 & 0.3282020 & $\mathbf{1 3 : 2 0 : 2 3}$ & 2.4942020 & $\mathbf{2 1 : 1 5 : 2 3}$ & 4.5022020 \\
9:29:24 & 0.3282020 & $\mathbf{1 3 : 2 0 : 3 3}$ & 2.5002020 & $\mathbf{2 1 : 1 5 : 3 3}$ & 4.5342020 \\
9:29:34 & 0.3342100 & $\mathbf{1 3 : 2 0 : 4 2}$ & 2.5092020 & $\mathbf{2 1 : 1 5 : 4 2}$ & 4.5652020 \\
9:30:25 & 0.3353890 & $\mathbf{1 3 : 2 0 : 5 2}$ & 2.5182020 & $\mathbf{2 1 : 1 5 : 5 2}$ & 4.5942020 \\
9:30:34 & 0.4214000 & $\mathbf{1 3 : 2 1 : 1}$ & 2.5272020 & $\mathbf{2 1 : 1 6 : 1}$ & 4.6192020 \\
9:30:50 & 0.4512679 & $\mathbf{1 3 : 2 1 : 7}$ & 2.5402020 & $\mathbf{2 1 : 1 6 : 7}$ & 4.6412020 \\
\hline
\end{tabular}

The average results for data collection in four days were summarized in table 4 and figure 5. In figure 5, the x-axis shows the kWh value and the $y$-axis consists of the collected data in four days in morning, afternoon, and night. From the bar chart, the energy consumption shows highest usage at night while the energy consumed in the morning, least energy usage was tabulated. The power usage at night is high because the household use the air conditioner and light (Li et al, 2009). For these four days data, the power usage in the morning maintain at an average of $0.90 \mathrm{kWh}$ while in the evening the power usage maintained at $2.0 \mathrm{kWh}$ and at night the power usage maintained at $4.0 \mathrm{kWh}$.

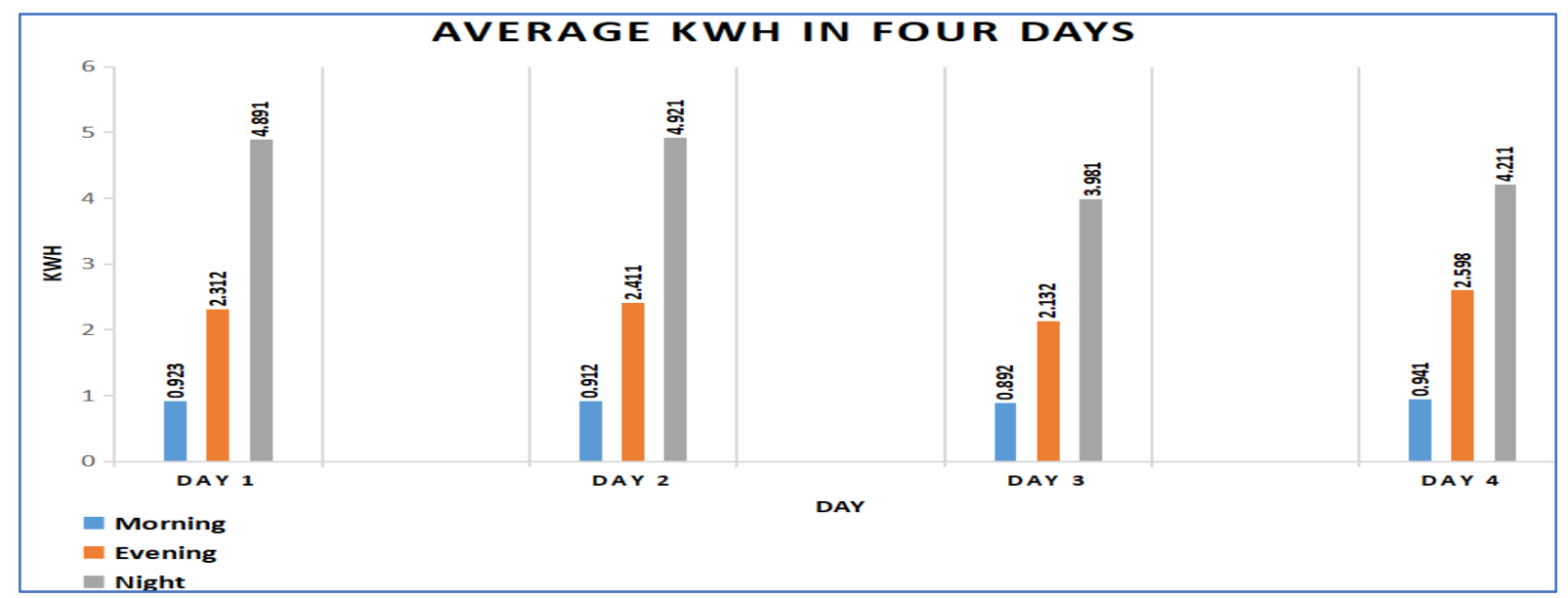

Figure 5: The bar chart result in four days 
INTERNATIONAL JOURNAL OF ACADEMIC RESEARCH ECONOMICS AND MANAGEMENT SCIENCES Vol. 11, No. 1, 2022, E-ISSN: 2226-3624 ㄷ 2022 HRMARS

Table 4: The average result kWh for four days

\begin{tabular}{lllll}
\hline & Day 1 & Day 2 & Day 3 & Day 4 \\
\hline Morning & $0.923 \mathrm{kWh}$ & $0.912 \mathrm{kWh}$ & $0.892 \mathrm{kWh}$ & $0.941 \mathrm{kWh}$ \\
Evening & $2.312 \mathrm{kWh}$ & $2.411 \mathrm{kWh}$ & $2.132 \mathrm{kWh}$ & $2.598 \mathrm{kWh}$ \\
Night & $4.891 \mathrm{kWh}$ & $4.921 \mathrm{kWh}$ & $3.981 \mathrm{kWh}$ & $4.211 \mathrm{kWh}$ \\
\hline
\end{tabular}

\section{Section B: Result for hardware testing at household appliances}

The power consumption pattern was observed on three different appliances for three different categories which are motor load for refrigerator, heating element load for electric oven and electronic load for LCD television at single phase 230V. The power consumption of each appliance was recorded for every 15 second interval for a period.

\section{Refrigerator}

Toshiba brand was used as tested appliance for refrigerator. Figure 6 illustrates the graph of refrigerator power consumption against time for interval of 90 minutes. From the graph in Figure 6 , there was a long duration spark of power at the region marked as 'compressor on' indicated that compressor and the fan motor started working at average of $200 \mathrm{~W}$ for 55 minutes. Then the compressor stops working after the refrigerator achieves the desired temperature. From the graph in Figure 6, at the red marked region of 'compressor off', the average refrigerator power usage run was $110 \mathrm{~W}$. During data collection process, the door of refrigerator was opened randomly to act as a normal daily life. As a result, the short spark of power aligns with the door opened. This condition was due to the increase of convection heat transfer inside refrigerator. Warm and moist air transferred from the outside surrounding mixes with the cabinet cool air. Hence, energy required to cool down again since the temperature inside of refrigerator dropped due to mix of warm air (Lu et al, 2019). The average power consumption during the door opened was between $100 \mathrm{~W}$ to $130 \mathrm{~W}$. The result show that the compressor turned on and the door opened required power consumption. The average power consumption was compared with the refrigerator wattage specification as stated in Figure 7. The result was the average power consumption during the normal condition was still in below of the rated power.

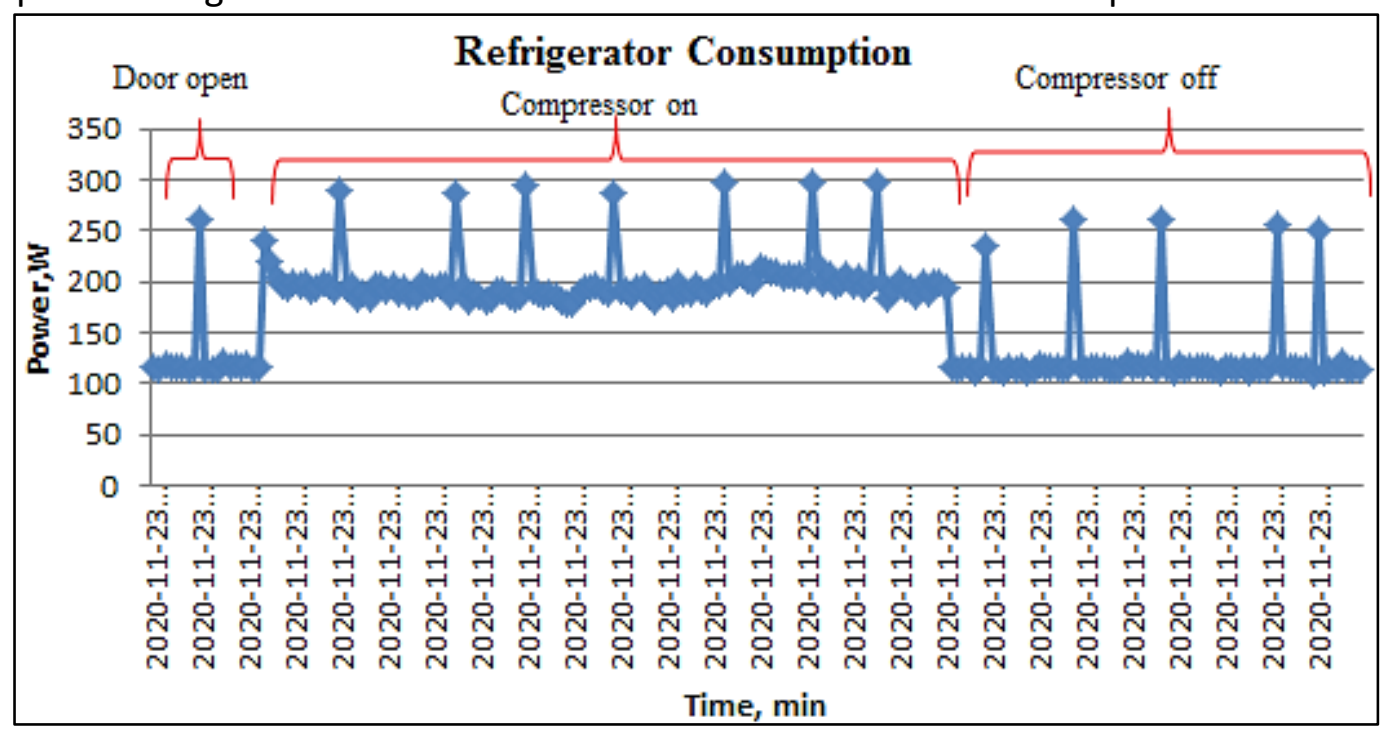


Figure 6: Refrigerator consumption

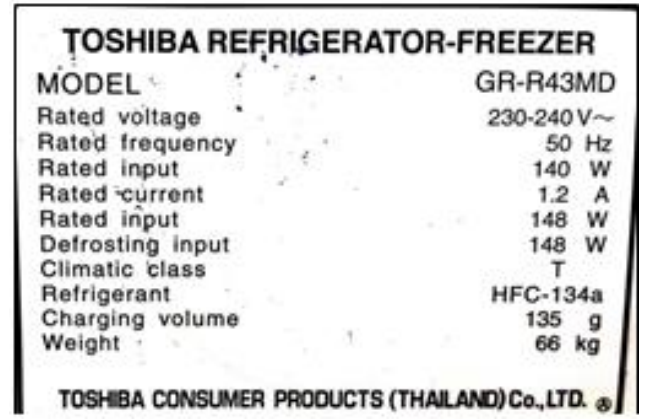

Figure 7: Refrigerator wattage specification

\section{Electric Oven}

Pensonic brand was used as tested appliance for electric oven. Figure 8 illustrates the graph of electric oven power consumption against time for a certain period. The total time interval for electric oven data collection was 15 minutes. From the graph in Figure 8, the sudden power increased when the temperature and the timer was turned on. The temperature was set at $70^{\circ}$ $\mathrm{C}$ origin and slowly increased until $190^{\circ} \mathrm{C}$ for 10 minutes. The result of the graph at the red marked region of 'temperature $\mathrm{ON}^{\mathrm{N}}$ ' does not show the noticeable of sudden increased of power. The average power consumption was $1140 \mathrm{~W}$. After 10 minutes, as the temperature has been decreased until $70^{\circ} \mathrm{C}$, the power was decreased until at a constant $40 \mathrm{~W}$ as show in Figure 4.5 at the red marked region of 'temperature OFF'. The average power consumption was compared with the electric oven wattage specification as stated in Figure 9. The result was the average power consumption was still below of the rated power.

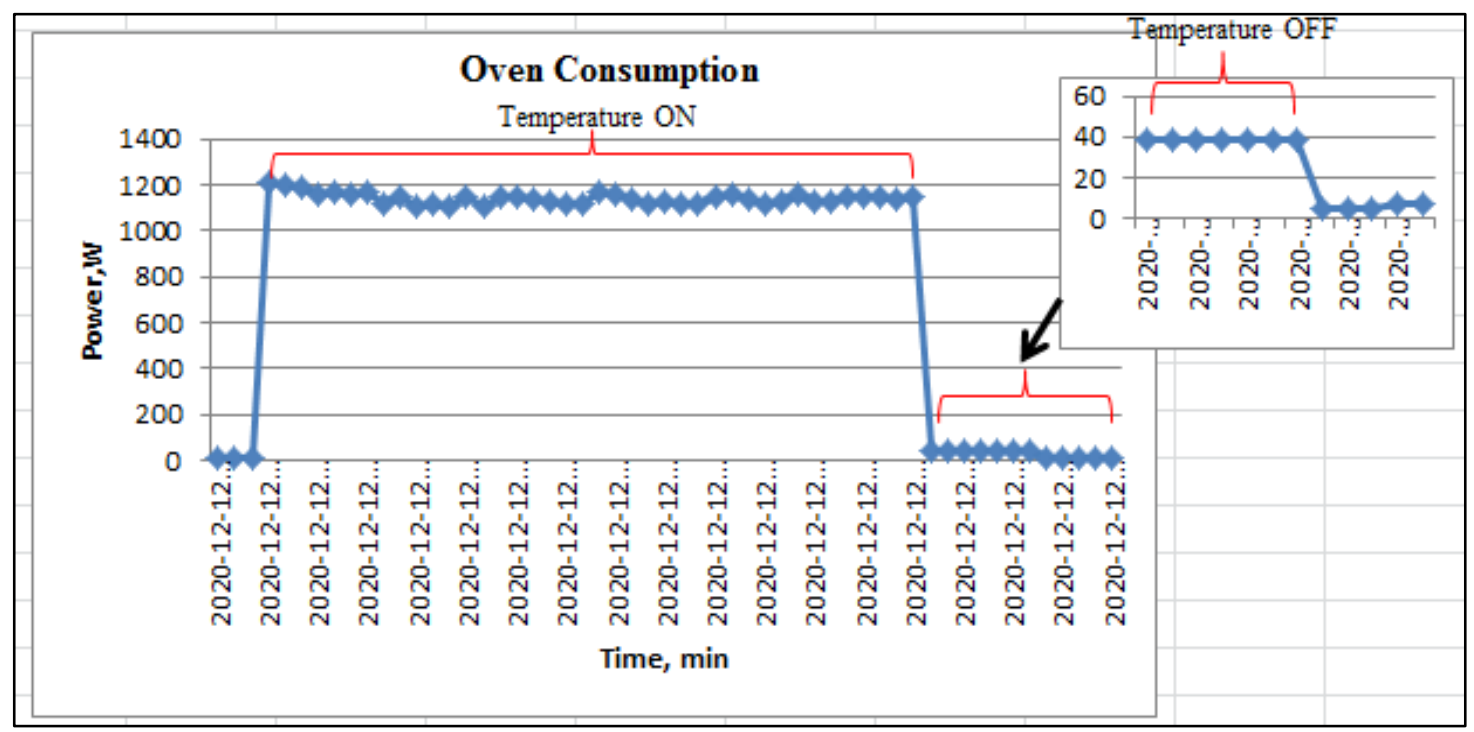

Figure 8: Electric oven consumption 


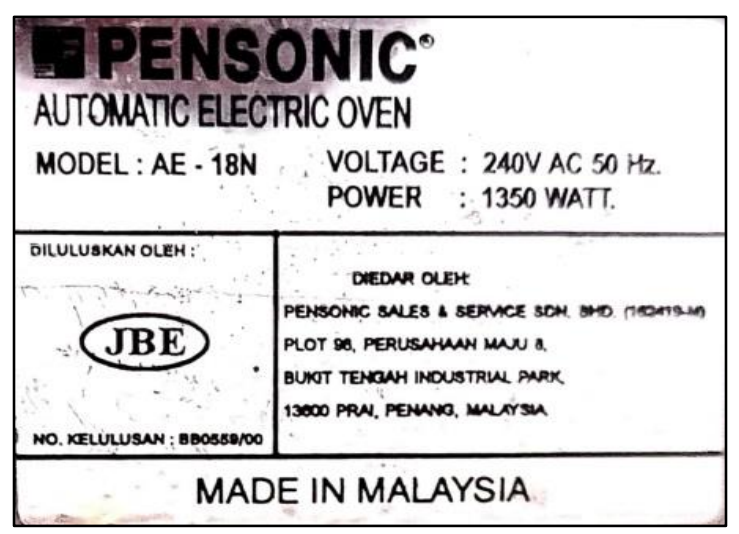

Figure 9: Electric oven wattage specification

\section{LCD Television}

LG brand was used as tested appliance for LCD television. Figure 10 illustrates the graph of LCD television power consumption against time for a certain period. The total time interval for LCD television data collection was 15 minutes. From the graph in Figure 10, at the red marked region of 'standby mode' was the situation when the television was opened in standby mode operation. There was power consume during the standby mode which at average of $33 \mathrm{~W}$. This is because standby mode allows the television using a little electricity to constantly read the signal from the remote control so that the television was ready to be turned on (Mitra et al, 2016). The power increased as the television was turned on as shown in Figure 10 at the red marked region of 'turn $\mathrm{ON}^{\prime}$. The average power consumption during the television turned on was at 93W. The average power consumption was compared with the electric iron wattage specification as stated in Figure 11. The result was the average power consumption was still below of the rated power.

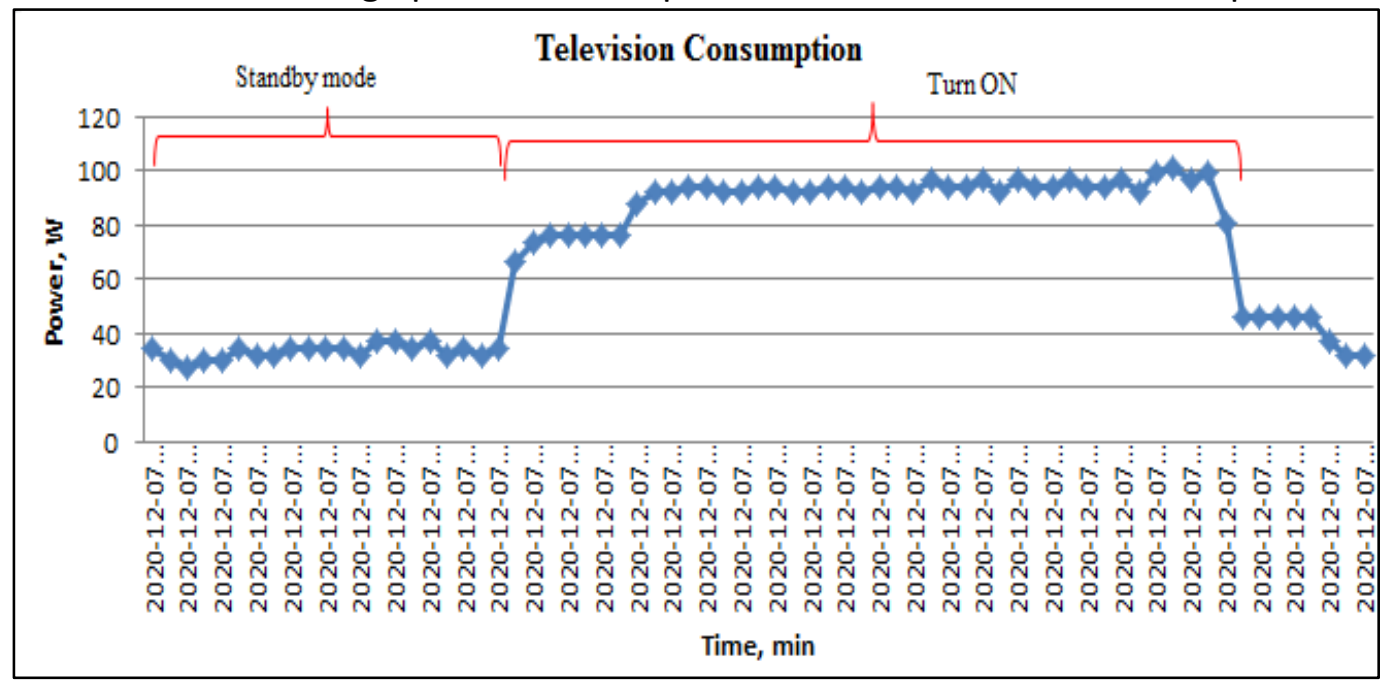

Figure 10: Television consumption 


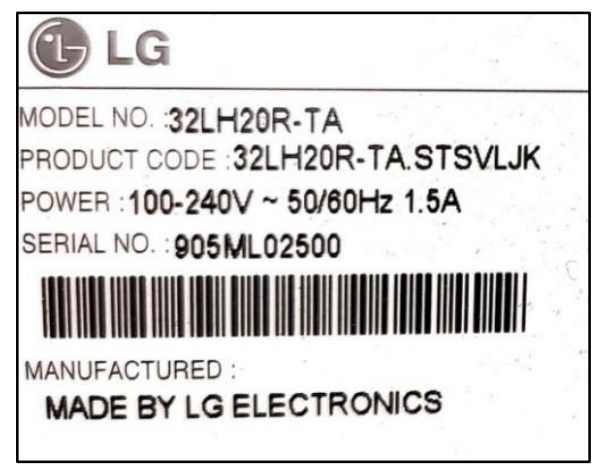

Figure 11: Television wattage specification

Based on the three categories of appliances, the highest power consumption was the heating element type appliances which is the electric oven with an average power consumption of $1140 \mathrm{~W}$ as compared to the refrigerator and LCD television with an average power of 200W and $33 \mathrm{~W}$ respectively. This is due to the current flows in the heating elements encounter resistance to convert the electrical energy into heat energy. Basically, it requires more current as compared to resistance in order to produce maximum heat energy (Pipattanasomporn et al, 2014)

\section{Section C: Notification through Blynk}

In this section, the result of power and energy reading notification from the Blynk apps will be explained. Blynk apps can be downloaded at an Android play store or IOS apple store. During the testing the device baseline was set to $3 \mathrm{kWh}$ and hence when the power reached the baseline the device will send notification to notify the user to the mobile phone via Blynk apps as shown in Figure 6. A strong internet connection is needed to collect the power reading from the residency energy meter as well as to monitor the live reading. From figure 6 , as the power exceeded the set limit, the Blynk app will send notification through mobile phone by displaying "Alert!!Reach the limit!!" to notify and alert the users about their consumption. Figure 8 shows the result of power and energy reading from Blynk apps defined from every second detected from the pulse reading.

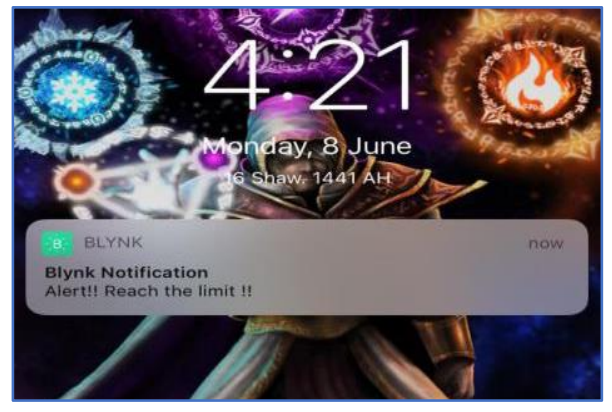

Figure 6: Example Notification through Blynk 


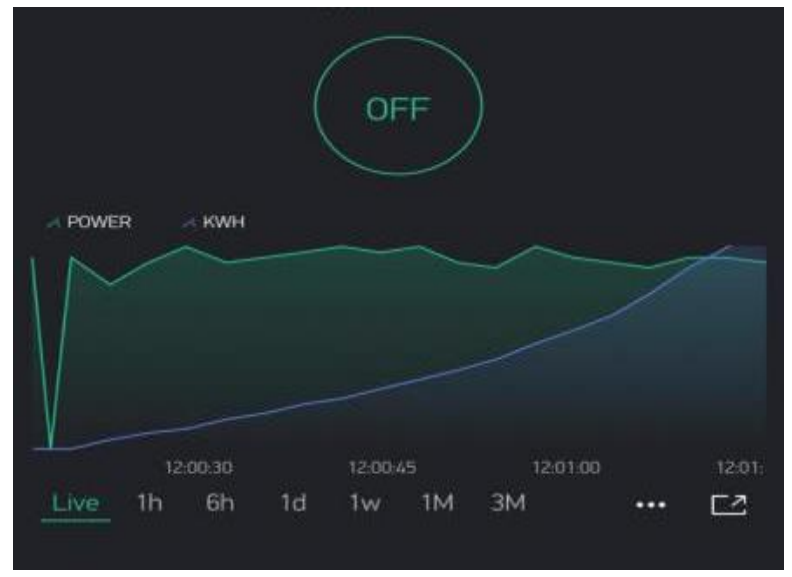

Figure 7: The result from Blynk apps

This data was taken during the Movement Control Order (MCO) in Malaysia due to pandemic Covid-19 situation worldwide. From the first wave of the disease in Malaysia from $25^{\text {th }}$ January 2020 to $27^{\text {th }}$ February 2020 (Naderipour et al., 2020) only 22 total cases were reported with 20 patients were from the imported cases and only 2 cases were local transmission. All the patients were discharged well after a handful treatment. Soon after the first Covid-19 wave and following 11 days of zero reported case, the second wave hit Malaysia tremendously on $27^{\text {th }}$ February 2020 (Shah et al., 2020) and most of the cases came from a Tabligh gathering in Seri Petaling. When the total number of positive cases hit 553 cases on $16^{\text {th }}$ March 2020 (DG of Health, 2020), the Prime Minister announced the first phase of Movement Control Order (MCO) for 14 days from 18th till 31st March 2020 (Ashley Tang, 2020). Malaysia has the total number of 7 MCO phases which are Phase 1 - Movement Control Order (MCO) from 18th till 31st March 2020 (14 days), Phase 2 - Movement Control Order (MCO) from 01st till 14th April 2020 (14 days), Phase 3 - Movement Control Order (MCO) from 15th till 28th April 2020 (14 days), Phase 4 - Movement Control Order (MCO) from 29th till 3rd May 2020 (5 days), Phase 5 - Conditional Movement Control Order (CMCO) from 4th till 11th May 2020 (8 days), Phase 6 - Conditional Movement Control Order (CMCO) from 12th May 2020 till $9^{\text {th }}$ June 2020 (29 days), Phase 7 - Recovery Movement Control Order (RMCO) from 10th June till 31th August 2020. Hence this project can help in giving an average value for energy consumption during MCO and thus preventing the spike in the monthly electricity bill.

\section{Conclusion}

Implementing this project helps users focusing more on how by using the loT could assist in building a smart energy meter to supervise their energy consumption. Other than that, during the peak and off-peak hours, consumer will be able to monitor their electricity availability in the easiest way which is by using the mobile phone. Consumers can be more aware of their energy usage anywhere and anytime. Thus, can help saving the monthly bill of the electricity. This project also able to detect the reading of the energy meter of the Power and Energy through the pulses number in every 30 minutes which they can log in and monitor their energy usage. Moreover, it helps to notify the users when the power is surpassing the limit that has been set by the user as well as the involvement of IoT delivers a huge improvement to the users' daily life in handling the 
INTERNATIONAL JOURNAL OF ACADEMIC RESEARCH ECONOMICS AND MANAGEMENT SCIENCES

Vol. 11, No. 1, 2022, E-ISSN: 2226-3624 ㄷ 2022 HRMARS

energy consumptions. Consumers will receive the notifications through mobile phone via the Blynk app when the power limit is exceeded.

\section{References}

Abate, F., Carratu, M., Liguori, C., \& Paciello, V. (2019). A low cost smart power meter for loT. Measurement, 136, 59-66. https://doi.org/https://doi.org/10.1016/j.measurement.2018.12.069

Alahakoon, D., \& Yu, X. (2016). Smart Electricity Meter Data Intelligence for Future Energy Systems: A Survey. IEEE Transactions on Industrial Informatics, 12(1), 425-436. https://doi.org/10.1109/TII.2015.2414355

Avancini, D. B., Rodrigues, J. J. P. C., Martins, S. G. B., Rabêlo, R. A. L., Al-Muhtadi, J., \& Solic, P. (2019). Energy meters evolution in smart grids: A review. Journal of Cleaner Production, 217, 702-715. https://doi.org/https://doi.org/10.1016/j.jclepro.2019.01.229

Aziz, N. A., Othman, J., Lugova, H., \& Suleiman, A. (2020). Malaysia's approach in handling COVID19 onslaught: Report on the Movement Control Order (MCO) and targeted screening to reduce community infection rate and impact on public health and economy. Journal of Infection and Public Health, 13(12), 1823-1829.

https://doi.org/https://doi.org/10.1016/j.jiph.2020.08.007

Bansal, P., Vineyard, E., \& Abdelaziz, O. (2011). Advances in household appliances- A review. Applied Thermal Engineering, 31(17-18), 3748-3760. https://doi.org/10.1016/j.applthermaleng.2011.07.023

Cebe, M., \& Akkaya, K. (2019). Efficient certificate revocation management schemes for loTbased advanced metering infrastructures in smart cities. Ad Hoc Networks, 92, 101801. https://doi.org/https://doi.org/10.1016/j.adhoc.2018.10.027

Diamantoulakis, P. D., Kapinas, V. M., \& Karagiannidis, G. K. (2015). Big Data Analytics for Dynamic Energy Management in Smart Grids. Big Data Research, 2(3), 94-101. https://doi.org/https://doi.org/10.1016/j.bdr.2015.03.003

Fettermann, D. C., Cavalcante, C. G. S., Ayala, N. F., \& Avalone, M. C. (2020). Configuration of a smart meter for Brazilian customers. Energy Policy, 139, 111309.

https://doi.org/https://doi.org/10.1016/j.enpol.2020.111309

Hasanuzzaman, M., Saidur, R., \& Masjuki, H. H. (2008). Investigation of Energy Consumption and Energy Savings of Refrigerator-Freezer During Open and Closed Door Condition. October. https://doi.org/10.3923/jas.2008.1822.1831

Kim, S., Kwon, E. Y., Kim, M., Cheon, J. H., Ju, S., Lim, Y., \& Choi, M. (2011). A Secure SmartMetering Protocol Over Power-Line Communication. IEEE Transactions on Power Delivery, 26(4), 2370-2379. https://doi.org/10.1109/TPWRD.2011.2158671

Kishore, S., \& Snyder, L. V. (2010). Control Mechanisms for Residential Electricity Demand in SmartGrids. 443-448. https://doi.org/10.1109/smartgrid.2010.5622084

Li, L., Hu, X., \& Zhang, W. (2009). Design of an ARM-based power meter having WIFI wireless communication module. 2009 4th IEEE Conference on Industrial Electronics and Applications, 403-407. https://doi.org/10.1109/ICIEA.2009.5138237

Lu, H., Wu, X., \& Liu, Q. (2019). Energy metering for the urban gas system: A case study in China. Energy Reports, 5, 1261-1269.

https://doi.org/https://doi.org/10.1016/j.egyr.2019.09.001 
Mitra, K., \& Dutta, G. (2016). Electricity Consumption Scheduling with Energy Storage , Home based Renewable Energy Production and A Customized Dynamic Pricing Scheme Keywords. Research and Publication.

Mudaliar, M. D., \& Sivakumar, N. (2020). IoT based real time energy monitoring system using Raspberry Pi. Internet of Things, 12, 100292. https://doi.org/https://doi.org/10.1016/j.iot.2020.100292

Muralidhara, S., Hegde, N., \& PM, R. (2020). An internet of things-based smart energy meter for monitoring device-level consumption of energy. Computers \& Electrical Engineering, 87, 106772. https://doi.org/https://doi.org/10.1016/j.compeleceng.2020.106772

Naderipour, A., Abdul-Malek, Z., Ahmad, N. A., Kamyab, H., Ashokkumar, V., Ngamcharussrivichai, C., \& Chelliapan, S. (2020). Effect of COVID-19 virus on reducing GHG emission and increasing energy generated by renewable energy sources: A brief study in Malaysian context. Environmental Technology \& Innovation, 20, 101151. https://doi.org/https://doi.org/10.1016/j.eti.2020.101151

Pipattanasomporn, M., Kuzlu, M., Rahman, S., \& Teklu, Y. (2014). Load profiles of selected major household appliances and their demand response opportunities. IEEE Transactions on Smart Grid, 5(2), 742-750. https://doi.org/10.1109/TSG.2013.2268664

Pocero, L., Amaxilatis, D., Mylonas, G., \& Chatzigiannakis, I. (2017). Open source loT meter devices for smart and energy-efficient school buildings. HardwareX, 1, 54-67. https://doi.org/https://doi.org/10.1016/j.ohx.2017.02.002

Rafsanjani, H. N., \& Ghahramani, A. (2020). Towards utilizing internet of things (loT) devices for understanding individual occupants' energy usage of personal and shared appliances in office buildings. Journal of Building Engineering, 27, 100948. https://doi.org/https://doi.org/10.1016/j.jobe.2019.100948

Rafsanjani, H. N., Ghahramani, A., \& Nabizadeh, A. H. (2020). iSEA: loT-based smartphone energy assistant for prompting energy-aware behaviors in commercial buildings. Applied Energy, 266, 114892. https://doi.org/https://doi.org/10.1016/j.apenergy.2020.114892

Shah, A. U. M., Safri, S. N. A., Thevadas, R., Noordin, N. K., Rahman, A. A., Sekawi, Z., Ideris, A., \& Sultan, M. T. H. (2020). COVID-19 outbreak in Malaysia: Actions taken by the Malaysian government. International Journal of Infectious Diseases, 97, 108-116. https://doi.org/https://doi.org/10.1016/j.ijid.2020.05.093 